\title{
Mitos y archivos: recientes paradigmas de la teoría comparativa en América Latina'
}

Biagio D'Angelo

Universidad Católica Sedes Sapientiae / PUCP Lima (Perú)

\begin{abstract}
Aureliano Babilonia no abandonó por mucho tiempo el cuarto de Melquíades. Se aprendió de memoria las leyendas fantásticas del libro descuadernado, la síntesis de los estudios de Hermann, el tullido; los apuntes sobre las ciencias demonológicas, las claves de la piedra filosofal, las centurias de Nostradamus y sus investigaciones sobre la peste, de modo que llegó a la adolescencia sin saber nada de su tiempo, pero con los conocimientos básicos del hombre medieval.

Gabriel García Márquez, Cien años de soledad
\end{abstract}

El lugar ocupado por los conceptos de Mito y Archivo en la teoría literaria actual, según las definiciones de Derrida, Foucault, y sobre todo a partir de la lectura que González Echevarría aporta a la teoría narrativa latinoamericana, se presenta como uno de los factores más interesantes y discutidos de la metodología comparativa aplicada al complejo universo latinoamericano.

Los últimos decenios han asistido a un renacimiento de relecturas, reconsideraciones, revisiones que han observado en el tránsito (no demasiado obvio) de la modernidad a la postmodernidad, un sistema creativo bastante compacto, una renovada periodización cultural que ha encontrado su justificación en una toma de conciencia de la pertenencia a un continente latinoamericano unitario y diverso al mismo tiempo.

Por largo tiempo la crítica comparatista ha persistido en considerar a Latinoamérica como en posición subsidiaria respecto a la práctica comparatista europea. Mario Valdés, encarado opositor de aquella mirada conservadora que considera Latinoamérica como difícilmente susceptible de ser "comparable", intenta una respuesta: si de un lado, una de las razones de esta dificultad podría ser localizada en la persistencia de un discurso hegemónico occidental, del otro, existe también la exigencia vetusta y superficial de que el acto del comparar requeriría textos originalmente compuestos, por lo menos, en dos idiomas distintos. Por último, se añade otra idea, errada y fuertemente limitadora, de una Hispanoamérica que cubre naciones del hemisferio sur y excluye toda el área caribeña; así como el olvido en definitiva del rico y original mundo de lengua portuguesa. Así formulada, la comparación literaria en América Latina asume, entonces, un aspecto polémico y, sin duda, novedoso en la consideración de las múltiples culturas y literaturas que ocupan el espacio lingüístico hispano-portugués. Aunque no considere en este trabajo las culturas así llamadas "minoritarias" (cultura quechua, aymará, maya, azteca, etc.) por ser un problema grave y al cual sería necesario dedicar una atención 
mucho más detallada, me detengo sobre una sugestiva lectura sintética del continente latinoamericano por Maria Elena de Valdés:

Latin America is a fictional space, forever in between the hegemonic domination of North

America and nostalgia for Europe. This in-between space is populated with voices of such diversity that the wildest fabulations of the first European visitors are but a remote and pale simulacrum. Latin America does not only speak in Spanish and Portuguese, but also in Creole and in Quechua, Nahuatl, Guaraní...2

En definitiva, no es del todo equivocado afirmar que la búsqueda literaria sobre el continente latinoamericano se concentra casi exclusivamente sobre aquella obsesiva tematización, como la define en un estudio reciente Luisa Campuzano, del problema de la identidad cultural. De hecho, la relación con Europa y, en primer lugar, con el mundo cultural barroco, el primero en alcanzar estas latitudes, es observada según una dicotomía orientada habitualmente a descentrar el viejo continente de su predominancia cultural y a preferir el aporte "autóctono" de los países "colonizados". Escribe Campuzano:

Para algunos, esa subjetividad transcultural encarna una herencia colonial de alienación; para otros, constituye la esencia misma de la cultura en América. Elegir un lado u otro de esta dicotomía determina lecturas muy diferentes. ${ }^{3}$

Si es verdad que Lezama Lima acepta el origen europeo de su propio arte, sin el cual no se hubiera producido ningún desarrollo histórico, y Carpentier, en la introducción escrita para El reino de este mundo (1949) afirma que el arte barroco ("un arte que consiste en retablos y árboles frondosos, de madera y altares") siempre ha sido latinoamericano, resulta fundamental para nuestro discurso la observación de González Echevarría según el cual la novela latinoamericana, virada la fase naturalista decimonónica, se moderniza y se centra sobre "la antropología como discurso hegemónico que hace posible la narrativa latinoamericana": era esa razón que permitiría a Carpentier declarar que el nuevo arte ocuparía la función de enseñar, mostrar, comunicar lo prodigioso de las cosas "naturales" de Latinoamérica.

El axioma "pedagógico" de Carpentier y las funciones críticas descubiertas por González Echevarría ofrecen un nuevo y decisivo rumbo hacia una teoría comparativa en Latinoamérica, ignorada hasta entonces, que podría desempeñar roles y trazar mapas renovados en el sistema literario.

La percepción de una literatura que se revela fabricante de mitos sobre su origen cultural se acompaña del descubrimiento de la autoridad (en el sentido de "posibilidad de ser autor") y de la capacidad de "generar un discurso que contenga y exprese esos mitos". ${ }^{4}$ Textos fundadores de esta teoría como Doña Bárbara y Los pasos perdidos adquieren legitimidad porque imitan "los textos que constituyen el discurso antropológico y la trama subyacente de escape de la hegemonía -el subtextoprocede de textos antropológicos".

Esta fórmula permite que el texto $y$, por ende, la cultura se conciban como pluralidad, una mirada que no procede exclusivamente de cómo los colonizadores miraban lo "local", sino también de cómo se expresaba el nativo, en búsqueda del conocimiento que el indígena (lo local, el nativo) posee, dice, revela como alteridad.

La antropología surgió como una disciplina capaz de integrar a los estados y la conciencia latinoamericanos, las culturas de pueblos no europeos que aún estaban muy presentes en el Nuevo Mundo, ese Otro interno analizado por Sarmiento y Euclides da Cunha. (...) La antropología también ofrecía a los países latinoamericanos la posibilidad de proclamar un origen propio distinto del de Occidente; un nuevo inicio que permitía alejarse del desplome de la civilización occidental que la guerra suponía. El conocimiento antropológico podía corregir los errores de la conquista, expiar los crímenes del pasado y conducir a una nueva historia. (...) El conocimiento antropológico proporcionó a la narrativa latinoamericana una 
fuente de relatos, así como una fábula maestra sobre la historia latinoamericana. En la ficción, la historia latinoamericana se moldeará ahora en forma de mito, una forma derivada de los estudios antropológicos. ${ }^{6}$

En una constante oscilación entre "prolongaciones" y "transgresiones”, de las que, sin embargo, está tejida toda la historia del pensamiento humano, la literatura latinoamericana presenta comparativamente un marco metaliterario muy rico y variado que, mediado por la antropología, afirma la necesidad de la escritura ficcional como tentativa de respuesta a la búsqueda de unidad en la diversidad latinoamericana: "El Archivo absorbe la autoridad de la mediación antropológica (...) La narrativa invalida la postura del metadiscurso, al mostrar que siempre forma parte de lo mítico", escribirá adecuadamente González Echevarría. ${ }^{7}$

De Miguel Ángel Asturias a Carlos Fuentes, de Carlos Germán Belli a Guillermo Cabrera Infante, de Haroldo de Campos a Oswald de Andrade, esta abundante vegetación literaria no es una mera acumulación de textos, sino que representa la recolección caótica (en búsqueda de un orden) de textos documentales y ficticios que, recuperando (y criticando) todo lo histórico, se convierten en materiales privilegiados del Archivo.

El material textual de la ficción latinoamericana encuentra su orden en un Archivo, cuyo contenido no es cronológico, sino "escritural". La escritura lujuriosa, que, como escribe Severo Sarduy, "refleja estructuralmente la inarmonía, la ruptura de la homogeneidad, del logos en tanto absoluto", se propone como narración "del desequilibrio, reflejo estructural de un deseo que no puede alcanzar a su objeto, deseo para el cual el logos no ha organizado más que una pantalla que esconde la carencia", 8 esta misma narración, desde el Archivo, pretende funcionar unitariamente y al mismo tiempo ser epistemológicamente una memoria implacable que mezcla y quiebra los relatos míticos de las formas ficcionales, la historia de la literatura, la oralidad de la escritura.

La escritura representa, en definitiva, lo que permite ordenar el Archivo, un Archivo que "no privilegia la voz del conocimiento antropológico" y que más bien resulta ser un "facsímile" de la ausencia del centro, tan comprometida con el discurso deconstruccionista. Se reconoce, entonces, cuáles son las ficciones del archivo, cuya función es determinar una taxonomía que sirva a la "textura" de la identidad de la cultura latinoamericana: Rayuela, Terra nostra, Yo el supremo, De dónde son los cantantes, Paradiso, Noticias del Imperio, son los ejemplos de la connotación epistemológica sintetizada por González Echevarría:

El Archivo no es tanto una acumulación de textos sino el proceso mediante el cual se escriben textos; un proceso de combinaciones repetidas, de mezclas y entremezclas regidas por la heterogeneidad y la diferencia. No es estrictamente lineal, pues la continuidad y la discontinuidad permanecen unidas en precaria alianza. Este archivo ficticio, desde luego, es como volver al revés el Archivo en su manifestación política, lo que revela el funcionamiento interno de la acumulación de poder; acumulación y poder no son sino un efecto retórico en este archivo de archivos. (...) No son arquetipos, sino un arché de tipos. ${ }^{9}$

En el conjunto de “arché de tipos” Miguel Ángel Asturias, Guillermo Cabrera Infante, Alejo Carpentier, Carlos Fuentes, Augusto Roa Bastos, sin olvidar la experiencia "antropófaga" brasilera, son aquellos autores que tropiezan en la experiencia de la crisis moderna, la analizan, la "archivizan" (en el sentido en que se vuelven archivo), sin poder desvincularse de aquel nexo estrecho y constante que es la sombra de la tradición europea.

Carpentier es el autor que más prepotentemente destina su reflexión sobre una metaliterariedad como "configuración" de un Archivo que intenta ordenar aquella "desfiguración" de la forma sensible y la fenomenalidad inmediata que han sido 
violentados, encadenados y esquematizados por la brutalidad de la historia.

La dimensión "archivística" de la obra de Carpentier encuentra su apogeo en la novela Los pasos perdidos, que González Echevarría define como un archivo de narraciones míticas, "un Archivo de relatos y un almacén de los relatos maestros producidos para narrar acerca de América Latina" ${ }^{10}$. Así, en Carpentier, y de manera especial en esta obra, el nexo entre Archivo y Mito es profundamente marcado. De una parte, el protagonista no puede borrar las huellas de su pasado; de la otra, su búsqueda se obstina en la composición de una narración nueva, original, que utópicamente debería fundarse como resultado de las varias tentativas precedentes. Así, Los pasos perdidos parece constituir la summa de lo imaginario latinoamericano, sintetizable en la idea de representar "la ficción del Archivo fundadora", a través del marco de una tipología barroca reinterpretada a luz del nuevo episteme cultural $^{11}$

Carpentier entiende por Barroco la mezcla de estilos en una misma obra, mezcla que corresponde a los diversos orígenes de cada estilo. El arte americano, que tiende siempre hacia el Barroco, exhibe esa mezcla de estilos, que es a la vez una especie de desfase temporal; lo neoclásico convive en la arquitectura de nuestras ciudades con vestigios mudéjares y el modern style. La mezcla desjerarquizada hace imposible que cada obra esté centrada en una idea que domine las demás. No es una amalgama cuya base metafórica sea la naturaleza, una especie de caos genésico de origen romántico, sino una convivencia de formas cuyo origen son las diversas culturas que ocupan el espacio americano. De ahí, la aparente desproporción permanente del arte americano, no sólo en cuanto al tamaño, sino en cuanto a la falta de equilibrio de las diversas partes. ${ }^{12}$

La ficción latinoamericana es, entonces, la creación de nuevos mitos, de nuevos relatos, por su necesidad de ser diferente y transgresora: el Archivo funda la creación de una amalgama histórica que aspira ser depósito mítico inteligible. "El archivo es un mito de mitos", declara González Echevarría, cuyas ficciones son necesariamente míticas porque "confieren a la figura del Archivo un poder arcano que es claramente originario e imposible de expresar, un secreto alojado en la expresión misma del Archivo". ${ }^{12}$

Las ficciones del Archivo se caracterizan por dos factores o estadios: el tropo de la muerte y la alegoría lúdica. La muerte, narrativizada y narrada, también a través de muertes en la escritura misma (huecos en los manuscritos, textos flotantes y perdidos, documentos depositados y privados de un sentido último homogéneo) revela la necesidad de una reunificación con un "lenguaje sagrado" que se ha irremediablemente suprimido por una nostalgia que busca obstinadamente satisfacción, cumplimiento, totalidad y que encuentra sólo desilusión, falta, desesperación.

El Archivo como mito es moderno porque es múltiple, relativista e incluso hace explícitos el relativismo y el pluralismo como cualidades inherentes de la literatura, el discurso hacia el que escapa. (...) La heterogeneidad de las culturas, lenguas, fuentes, comienzos, está en la esencia de la negatividad fundadora del Archivo, un pluralismo que es una subversión o una sub-versión de la fábula maestra. El Archivo recoge y suelta, no puede marcar o determinar.

El Archivo no puede erigirse en mito nacional o cultural, aunque su construcción sigue revelando un anhelo por la creación de un grandioso metarrelato político-cultural. ${ }^{14}$

Esta carencia de definitividad que el Archivo parece declarar, a pesar de su deseo de totalidad, pasa a través de una ulterior trasgresión: el manejo "lúdico" de la literatura como juego ficcional, único aparente motivo de novedad en la cultura de la "exhaustion", según la célebre definición de John Barth. Para Severo Sarduy, por ejemplo, el espacio y (siguiendo las sugerencias preciosas de González Echevarría) el Archivo se presentarían, entonces, como lugares: 
(...) de dialogismo, de la polifonía, de la carnavalización, de la parodia y la intertextualidad

(...) Red de conexiones, de sucesivas filigranas, cuya expresión gráfica no sería lineal, bidimensional, plana, sino en volumen, espacial y dinámica. ${ }^{15}$

Si consideramos, en cambio, el microcosmos de Macondo en Cien años de soledad, nos damos cuenta de que dentro del archivo juega un papel fundamental la memoria, una "memoria" que penetra los pliegos del material textual y de la realidad con la fuerza mágica de la escritura. Y así volvemos a la escritura, verdadera ordenadora del Archivo, y con ella a la memoria.

En la historia de Macondo y de los Buendía, la escritura metafóricamente posee la fuerza mágica de revelarse como herramienta vital, acto teúrgico, creador de vida y héroes; como en la literatura oral es la fuerza mnemónica de la oralidad y de la escucha que se transmite a través de los pergaminos de Melquíades, que cumplen su función lúdica y, al mismo tiempo, pedagógica. Por eso, el conocimiento maravilloso de Aureliano Babilonia empieza por la literatura, aprendiendo de memoria "las leyendas fantásticas del libro descuadernado", ${ }^{16}$ y dándose cuenta, en un proceso semiótico especial e indicativamente confuso, que "había leído de la primera página a la última, como si fuera una novela, los seis tomos de la enciclopedia” ${ }^{17}$ Reconstruir el pasado coincide con re-escribir la memoria, ordenando todo un material archivado por sedimentos mezclados, sin espacios comunes, ni puntos de entrelaces. Las intervenciones de González Echevarría permiten observar cuán estrecho es el vínculo entre memoria y archivo, y cómo el archivo funciona en cuanto generador incesante de mitos:

El Archivo es al mismo tiempo espacioso e incompleto. La espaciosidad, que se relaciona con la custodia y la función atávica de recinto del Archivo, es un reflejo de la fuerza totalizadora de la Ley. La ley de leyes lo contendría todo. Supuestamente, el manuscrito de Melquíades abarca toda la historia de la familia Buendía, es decir de Macondo y de todo el mundo ficticio de la novela. (...) La capacidad del Archivo, su totalización, es un emblema de su poder. El Archivo contiene todo el conocimiento; por lo tanto, es el depósito de todo el poder. ${ }^{18}$

La memoria caracteriza toda la representación ficcional latinoamericana, in primis, los autores que hemos citados en principio de este texto y cuya escritura ha sido encanalada dentro del flujo archivístico.

Las ficciones del Archivo también tratan sobre la acumulación de conocimiento y sobre la forma en que el conocimiento se organiza como cultura. En cuanto depósitos de conocimiento, las ficciones del Archivo son acumulaciones atávicas de lo establecido. A esto se debe que las ficciones del Archivo a menudo sean históricas y consistan en una compleja red intertextual que incorpora las crónicas del descubrimiento y la conquista de América, otras ficciones, documentos y personajes históricos, canciones, poesía, informes científicos, figuras literarias y mitos, en suma, una especie de piñata de textos con significado cultural. La organización del Archivo desafía la clasificación convencional porque la clasificación está en discusión, pero no abandona esta función básica del Archivo para generar una masa incipiente heteroglósica; una masa de documentos y otros textos que no se han asimilado por completo y, a veces, ni siquiera parcialmente, que retienen su existencia original en bruto, inalterada como prueba de la no asimilación del Otro. ${ }^{19}$

Cabrera Infante, por ejemplo, en su lúdico discurso narrativo, intenta reconstruir su pasado histórico y al mismo tiempo su Cuba mítica de la infancia y adolescencia. Cabrera Infante elige o recupera de su memoria algunos archivos de su amplio repertorio, archivos que preservan no sólo el olvido sino también la incursión vandálica de un sistema sociopolítico mentecato, que no usa la actividad de la memoria por miedo de deber cuestionarse al infinito. La selección que opera el autor cubano no es sino una mínima parte del juego de contraste de conflictos y 
tensiones que la memoria recordada y la memoria excluida, según los conceptos de Derrida ${ }^{20}$, llevan a cabo para rehabilitar la clandestinidad del archivo, en particular, de lo personal.

La memoria se mezcla con la Historia, penetra dentro de sus pliegos, molestándola, transformándola, invirtiendo la verdad y la ficción en un juego que escapa de una lectura monolítico-ficcional de lo literario. Augusto Roa Bastos pone en discusión, en su obra maestra, Yo el supremo, la historiografía oficial y construye su proyecto utilizando documentos memorialísticos y archivos que se convierten, como con precisión afirma Krysinski, en una "especie de contrahistoria":

Para asegurar el logro del discurso transhistórico, Roa Bastos recurre a la ficción del dictador dictando sus propias memorias y comentando su gobierno y sus éxitos históricos. Su discurso se convierte así en el discurso autónomo ficcional que contrasta con los dos documentos y, al mismo tiempo, con la historiografía oficial, siendo contrastado por su parte mediante el material compilado que manipula el narrador-compilador. ${ }^{21}$

Sería indispensable, quizás, a este punto, repensar en una nueva periodización o una relectura e interpretación del canon de la literatura latinoamericana como resultado de fuerzas, paradigmas, sinergias, como el fundamental eje diacrónico "barroco-neobarroco", que se cruzan, se entremezclan, se evitan, casi paralelas, a veces, en búsqueda de la formación de un Archivo definitivo y último.

En relación al eje neobarroco, cuyo discurso merecería una profundización mucho más amplia y detallada ${ }^{22}$, se puede observar que desde el archivo, la nueva escritura narrativa llega a rescatar también el modelo teatral: si bien ciertos poetas, como Carlos Germán Belli, utilizan casi humorísticamente formas poéticas vetustas como la silva o el madrigal, y presentan un léxico mixturado de términos áulicos a jerga cotidiana, la literatura de la segunda mitad del siglo XX está toda atravesada por la teatralidad, como afirma José María Pozuelo Yvancos sintetizando la actualidad del teatro barroco en nuestros días. ${ }^{23}$ Por su parte, Omar Calabrese, recuperando toda una lectura positiva del siglo barroco, recuerda que el signo posmoderno es por su naturaleza un signo "neobarroco" porque la cultura contemporánea habría rechazado la lectura romántica idealista, solipsista, narcisista, a favor de una figuralidad y de un uso nuevo del simulacro y habría aceptado sólo en parte las vanguardias modernistas ridiculizándolas a través del uso irónico de la cita intertextual. El espacio de la representación literaria se configura como discurso de teatralidad. ¿El archivo se configura él mismo como espacio o depósito de teatralidad?

El archivo sería representable con la imagen de un río oscuro, barroso, turbio de materiales ficcionales y documentales (como es el caso de la memoria lúdicamente autobiográfica de Cabrera Infante o la memoria fragmentada de Roa Bastos) en que la lengua se abre a efectos de saturación y absurdidades, de confusión caótica, de duda sistemática y de desorientación moral, según un procedimiento polémico y enfermizo que Sarduy define como "arte de descomponer un orden y componer un desorden". ${ }^{24}$ Así, en La guaracha del Macho Camacho, Luis Rafael Sánchez ironiza el texto de un bolero ("la vida es una cosa fenomenal...") que funge de base y referencia a unos acontecimientos que afirman lo contrario: la tragedia y la tristeza del vivir.

El regreso a la historia, casi siempre irónicamente interpretada, según la mixtura de juego teatral de las apariencias y cuestionamiento del vacío existencial, pasa del clavicémbalo de Scarlatti que suena en conjunto con los golpes abatidos sobre los esclavos, en Concierto barroco de Alejo Carpentier (1974), a la propuesta mítica de las estructuras narrativas en Santa Evita de Tomás Eloy Martínez (1995), en que Evita Perón, mito argentino y latinoamericano por excelencia, está presente en la novela desde el principio sólo como cadáver, en una "neobarroca" archivización de la muerte. 
En este proceso caníbal, antropófago, para decirlo con Oswald de Andrade, de ficciones y relatos, hacia la formación de una moderna mitología, el archivo se puebla de quimeras, de similitudes que, como sugiere Foucault, existen sólo como en perspectiva del error, del engaño que es la vida, donde "se dibujan las quimeras de la similitud", sin reconocerlas como quimeras. Foucault lo llama "el tiempo privilegiado del trompe-l'oeil, de la ilusión cómica"; es decir, aquel tiempo "de los sentidos engañosos; es el tiempo en el que las metáforas, las comparaciones y las alegorías definen el espacio poético del lenguaje”. ${ }^{24}$

La historia barroca y neobarroca de América arrastra, como un río desbordante, todo lo percibible y lo espiritual, empujándolos "hasta las puertas del paraíso", como diría Lezama Lima. Y dado que ese neobarroco es, en realidad, "desmesura" barroca, sería nuestra intención definir si el Archivo se resume finalmente en un proyecto utópico o en el mito del origen que Carpentier hallaría en Santa Mónica de los Venados. La búsqueda de una autonomía cultural latinoamericana resultaría, entonces, la connotación más explícita de la "actualidad" del archivo "comparativo" en el sistema cultural de este continente.

\footnotetext{
${ }^{1}$ El texto aquí presentado es la ampliación de una ponencia pronunciada en ocasión de las VI Jornadas Nacionales de Literatura Comparada de la Asociación Argentina de Literatura Comparada (Córdoba, agosto 2003) y que hace parte de un trabajo de investigación con el Grupo de Trabajo de Literatura Comparada de ANPOLL (Asociación Nacional Brasilera de Investigaciones sobre Lengua y Literatura), en la línea "Archivos sudamericanos", coordinada por la Dra. Maria Antonieta Pereira (Universidade Federal de Minas Gerais, Belo Horizonte).

${ }^{2}$ Véase la Introducción a Latin America as Its Literature, Selected Papers of the XIV th Congress of the International Comparative Literature Association, ed. by Maria Elena de Valdés, Mario Valdés and Richard A. Young, Council on National Literatures World Report editors, 1995, p. 5.

${ }^{3}$ Campuzano, L. (1999): "Traducir América: el código clásico en cinco novelas de Alejo Carpentier”, en Bañuls, J. V.; Sánchez, J. y Sanmartín, J. (eds.), Literatura iberoamericana y tradición clásica, Valencia, Universitat Autònoma de Barcelona-Universitat de València, pp. 100-110.

${ }^{4}$ GonzÁlez Echevarria, R. (2000): Mito y archivo. Una teoría de la narrativa latinoamericana, México, FCE, p. 199.

${ }^{5}$ Ibidem, p. 199.

${ }^{6}$ Ibidem, pp. 208-209.

${ }^{7}$ Ibidem, p. 212.

${ }^{8}$ SarduY, S. (1972): "Barroco y neobarroco", en Fernández-Moreno, C. (ed.), América Latina en su literatura, México, Siglo XXI, p. 183.

${ }^{9}$ González Echevarría, R.: Mito y archivo, op. cit., p. 53.

${ }^{10}$ Ibídem, p. 26.

${ }^{11} \mathrm{La}$ referencia es a la relectura, principalmente de Occidente, de la cuestión neobarroca como correlativo epistemológico de la crisis de la fe, de la política, de los ideales. Entre los aportes teóricos que han servido para fijar algunos fenómenos del controvertido mundo de la crisis de la modernidad, recordamos Buci-Glucksmann, C. (1984): La raison baroque. De Baudelaire à Benjamin, Galilée, Paris; Deleuze, G. (1988): Le pli.
} 
Leibniz et le Baroque, Minuit, Paris; Calabrese, O. (1989): La edad neobarroca, Madrid, Cátedra.

${ }^{12}$ González Echevarría, R. (1985): "Introducción” a Alejo Carpentier en Los pasos perdidos, Madrid, Cátedra, p. 37.

${ }^{13}$ González Echevarría, R.: Mito y archivo, op. cit., p. 239.

${ }^{14}$ Ibidem, p. 240.

${ }^{15}$ SarduY, S.: "Barroco y neobarroco", en Fernández-Moreno, C. (ed.) América Latina en su literatura, op. cit., p. 175.

${ }^{16}$ García Márquez, G. (1984): Cien años de soledad de Joset, J. (ed.), Madrid, Cátedra, p. 429.

${ }^{17}$ Ibidem, pp. 447-448.

${ }^{18}$ González Echevarría, R.: Mito y archivo, op. cit., p. 246.

${ }^{19}$ Ibidem, p. 241.

${ }^{20}$ Véase Derrida, J. (1997): Mal de archivo. Trad. Vidarte P., Madrid, Trotta.

${ }^{21}$ KRYSINSKI, W. (1998): La novela en sus modernidades. A favor y en contra de Bajtín, Frankfurt-Madrid, Vervuert-Iberoamericana, p. 183.

${ }^{22}$ Véase mi ensayo (2004) "El origen compartido. El discurso neobarroco en la literatura de América Latina”, D’Angelo, B. (org.), en Espacios y discursos compartidos en la literatura de América Latina, Fondo Editorial UCSS, Lima, de próxima publicación.

${ }^{23}$ Es el análisis publicado en Pozuelo Yvancos, J. M. (2000): "Calderón, el mundo como teatro", en ABC Cultural, 21 de abril, Madrid, pp.7-8. ${ }^{24}$ SarduY, S. (1973): Cobra, Sudamericana, Buenos Aires, 2da ed., p. 20. ${ }^{25}$ Foucault, M. (1972): Las palabras y las cosas. Una arqueología de las ciencias humanas, México, Siglo XXI, p. 58. 